moral or political bias, and it has to be employed even if the economist is asked to advise subject to some stated political objective, such as national self-sufficiency.

In addition to the system of prescriptions, traditional economics has provided a body of general laws relating to the sequence of events. These have been largely deductive, because they spring from a single simple principle, which has an empirical basis, but one derived from an immensely wide human experience, namely, the law of demand or the law of diminishing utility. This is almost axiomatic, and further investigations are unlikely to reinforce the authority it already has. By the aid of it and of its corollaries, it is possible to derive a theory of supply and demand, by which the effect of specified changes on the course of prices, wages, employment, etc., may in principle be determined. But this law and its corollaries are of very wide generality and consequently are of little use for prediction in any particular circumstances.

To have greater predictory power in this field, it would be necessary to be able to state the laws governing the demand for particular commodities, etc., in quantitative terms. Owing to the plurality of causes, it is extremely difficult to derive such laws from the data of observation. The quantitative laws would certainly be far more conjectural than the general qualitative results derived from the demand axiom. Interesting attempts have been made along these lines. But it is probable that the future of quantitative empirical economics lies elsewhere. Indeed the success of deductive reasoning up to a certain point has probably caused an excessive concentration of effort on this branch of the subject.

The wealth of recommendation, which has characterized past economics, may be reconciled with its paucity of predictory power, when it is appreciated that the power does not rest on the few general causal laws which we have, but on classificatory and survey work.

Contemporary study is seeking new approaches to the establishment of general causal laws, outside the ambit of the traditional laws of demand and supply. It is not yet certain whether greater success is likely to be obtained by the hypotheticaldeductive method, which must depend on suitable data being thrown up by the facts of the working world to take the place of the crucial experiment, or by a more radically empirical method, which seeks by constant study and re-classification of the facts to make them speak for themselves and suggest new laws.

In one field at least Mr. Harrod hopes for a further successful outgrowth of deductive theory. The laws of demand and supply, already referred to, which are sometimes known as 'static theory', may be compared with the laws of statics relating to bodies at rest. It should be possible to develop a system of laws, which by analogy may be called dynamic theory, relating to the behaviour of a system when the fundamental magnitudes, population, capital, etc., are increasing (or decreasing). Mr. Harrod suspects that we are on the verge of formulating one or two simple axioms, based on very wide experience and having almost as great an authority as the law of demand in static economics, from which a quite complicated set of laws relating to a system in motion may be derived. Such an axiom may be that people save a larger amount if they have a larger income. Since our society is in fact growing and not stationary, the hypotheses which theorists will be disposed to make in this department will be subject to easier verification than those of static theory.

This is, however, but one out of many possible lines of advance. A greater tendency towards the empirical may safely be predicted. Empirical work in economics is exceedingly laborious, and can only flourish if there is ample endowment for full-time research workers. The branch of statistical theory of especial use to empirical economists is at present displaying a welcome vitality.

Economists should be keenly alive to the findings of workers-sociologists, anthropologists, etc., on the periphery of their subject. But the suggestion recently put forward by one or two eminent persons that economics is in a parlous state requiring salvage by workers in sister subjeets is rejected with contempt. Of all the social studies, economics has been most successful in attaining valid general laws of interest and authority, and it is at the moment in a condition in which an advance over a wide front may reasonably be expected.

\section{Changing Outlook of Engineering Science}

IN Section G (Engineering), seeking a topic of $I_{\text {concern to both practising and academic members }}$ of his audience, the president, Prof. R. V. Southwell, undertakes a general stocktaking-to view the trend of engineering science regarded both as an art and as a field for study, teaching and research. He divides his presidential address into three main sections, dealing (1) with policy in regard to the teaching of engineering science, (2) with policy in regard to engineering research, and (3) with 'foreign policy' - the relation of the engineer to the community ; its keynote throughout being that in the changing circumstances of to-day engineers, whether practical or academic, must frame their policies in collaboration, not 
wait for action to be forced on them by pressure from without.

Among changing circumstances are (1) the trend of modern physics, (2) the attitude of industry towards the university graduate, and (3) the national organization for applied research : each has implications which no engineer can afford to neglect. In regard to the training of university students, which usually occupies five years divided between laboratory and works, he urges the desirability of planning for this period as a whole ; and he suggests that university courses are too often overloaded so that insufficient time is left for those divergent pursuits which do most to develop the personal qualities that industry has come to value. Matters appropriate for treatment in the lecture need not necessarily be included in the examination syllabus.

Engineering research, Prof. Southwell believes, will continue to be prosecuted in universities notwithstanding its increasing demand for specialized knowledge of mathematics, physics and chemistry, and the increased provision which now exists in Government institutions and in industrial research departments. Compared with professional physicists, chemists and mathematicians, academic engineers have a special point of view, and one that is needed. Their work will come to approximate more and more to what in the last century was called pure physics: schools of engineering will find problems different from those which engaged their energies a generation ago. When a problem can be turned over to trained men who will work on it full time, it is uneconomic both of brains and of money to pursue it at universities, in occasional spells of leisure from the duties of teaching and administration.

Under his last heading-public relations-Prof. Southwell utters a protest against an implication in much that is written nowadays, that because the range of engineering includes guns, battleships, aeroplanes, tanks, therefore engineers are to be regarded as a class more than others responsible for the horrors of modern war. Wars are not made by engineers but by communities: we all have responsibility, but as citizens and not as specialists. It is vain to talk as though we could have had the benefits of science without its risks and its temptations. Either we must choose, deliberately, impotence as preferable to the power of doing evil, or we must accept knowledge for the double-edged tool it is, vowing to use it wisely.

\section{The Orient and Europe}

THE distortions of prehistory on the Continent to fit "biased and distorted political dogmas" and the travesty of the subject broadcast by the
B.B.C. a year ago challenge archæologists to justify their membership of an association for the advancement of science by criticizing their hypotheses impartially and objectively in the light of rapidly accumulating concrete facts. Prof. V. Gordon Childe attempts such an examination in his presidential address to Section H (Anthropology).

Prehistory as expounded in Britain rests upon a complex of assumptions, collectively constituting the 'Orientalist position', classically formulated by Montelius in "Der Orient und Europa", published in 1899. His position involved the following assumptions: (1) civilization in the Orient is extremely ancient ; (2) civilization can be diffused ; (3) elements of civilization were in fact diffused from the Orient to Europe; (4) the diffusion of historically dated Oriental types provides a basis for bringing prehistoric Europe within the framework of historical chronology; (5) prehistoric European cultures are poorer than contemporary Oriental cultures, that is, civilization is later in Europe than in the East.

In 1899, all these propositions had to be treated as axioms. Now systematic excavation in Hither Asia and the Balkans has furnished experimental data by which the foregoing axioms can and must be tested.

(1) Excavations at Erech and Ur, Tel Asmer and Khafaje, Nineveh and Tepe Gawra have dramatically provided concrete proof of the immense antiquity of settled agricultural life in Mesopotamia. Estimated dates of the order of 6000 B.c. for the Tel Halaf phase that is separated from the earliest historical horizons by stupendous accumulations of settlement debris, are at least as plausible as similar geological estimates of the age of the North European mesolithic. Similarly, excavations at Alisar Hüyük, Troy and Thermi have vindicated the antiquity of metal-using cultures in Anatolia too.

(2) The exploration of Anatolia has also provided fresh evidence for cultural connexions with Mesopotamia. Taken in conjunction therewith, Heurtley's work in Macedonia has established irreversibly the Anatolian origin of the Macedonian Early Bronze Age culture. At the same time the 'Late Neolithic' culture, that immediately precedes and may partly overlap it, proves to be, to all intents and purposes, identical with that revealed at Vinča and other sites in the south-east of the Middle Danube basin. Thence culture is well known to be continuous right up to the Rhine, whither Mediterranean Spondylus shells were imported even in the first neolithic period or Danubian I. A cultural continuum can now be traced from the Tigris to the Rhine and affords opportunities for the diffusion assumed in axiom (2).

(3) Oriental prototypes for arbitrary forms of 